\title{
MOTION PLANNING OF ASSISTIVE EXOSKELETON IN HUMAN'S LOCOMOTION REHABILITATION
}

\author{
DUONG MIEN KA \\ Faculty of Electric Engineering Technology, Industrial University of Ho Chi Minh City \\ duongmienka@gmail.com
}

\begin{abstract}
Researches on rehabilitation exoskeleton system have bee
$\mathrm{n}$ implementing in recent decades and have been achieving many advantages. However, most of reseaches have focused on more simplified systems such as rehabilitation exoskeleton for one or two joints or for one paralysed leg with the purpose of recovering human's locomotion pattern. Researches on rehabilitation exoskeleton using for whole two paralysed legs are limited because of the complexity of balance issue for a combined human - exoskeleton system. Therefore, crutches are used to prevent the human from falling during human's walking in recent researches. In order to abandon the crutches and help to recover human's nomal walking pattern, the balance problem of combined human-exoskeleton system must be considered in control algorithm. In this paper, we build a motion path for a combined human-exoskeleton ensuring that the combined human-exoskeleton system can move in a balanced area. Our proposed paths are validated in the control algorithm for the HUALEX exoskeleton system in University of Electronic Science and Technology of China (UESTC).
\end{abstract}

Keywords. Rehabilitation exoskeleton, Human - Exoskeleton interaction, Locomotion Pattern Recovering.

\section{INTRODUCTION}

Researches on rehabilitation exoskeletons have been implementing in recent years all over the world. Most of researches come from Japan and China where elder persons that need assistive devices in their walking activites are increased day by day. Paralysed person as well as disabled persons can not walk by themselves without using assistive devices such as wheelchair, crutches. In addition, falling-down can result in serious injuries for the wearers. Therefore, researches on rehabilitation and assistive exoskeleton can benefit society and enhance life quality. The assistive exoskeleton is worn by the wearer's leg via soft belts at the specific locations. The movement of the wearer's leg is driven by the movement of the assistive exoskeleton. In this case, the exoskeleton is active and the wearer is passive during walking.Therefore, the goal of the controller in a such combined system is to control the assistive exoskeleton according to defined locomotion pattern in order to recover human walking pattern while keeping balance for the wearer during walking. The challenge in this case is that how to define the balance model for the controller. The balance issue in recent researches can be implemented by using crutches such as in $[1,2,3]$ or handrail in $[4,5]$. These researches have limitations that make the wearer unconfortable during walking as well as keep the crutches beside them all time. Some other researches focused on solving the balance issue without using any assistive devices during walking such as in $[6,7,8]$.

We recognize that the dynamic model of 3D pendulum can be applied into the motion planning of the assistive exoskeleton because of the similar dynamic characteristics between the inverted pendulum and the assistive exoskeleton. The control of a 3D inverted pendulum is a feasible choice that can be applied to the controller for the combined wearer exoskeleton system. In this paper, we suggest to use the dynamic model of 3D inverted pendulum [9] in order to establish the motion trajectories for the combined wearerexoskeleton system. The achieved results in this paper are validated on the controller of the real assisitve exoskeleton (named HUALEX) implemeneted in University of Electronic Science and Technology of China. This paper is organized in 4 sections; the dynamic model of the 3D inverted pendulum is addressed in section 2; section 3 mentions the center of mass analysis of the combined wearer-exoskeleton system; section 4 represents planned trajectories in a walking cycle for the combined system; the archieved results as well as conclusion section are represented in section 5 and 6 respectively. 


\section{DYNAMIC MODEL OF 3D INVERTED PENDULUM}

The three dimension linear inverted pendulum can be illustrated as in Figure 1. The mass of the pendulum is supported by the shaft swinging in three dimension space (3D). We denote $r$ is the length of pendulum shaft; $\beta_{p}$ is the angle between the shaft and yOz plane; $\beta_{r}$ is the angle between the shaft and $x O y$ plane. The position of the mass in Cartesian Co-ordinates system is represented by the vector $(\mathrm{x}, \mathrm{y}, \mathrm{z})$ while the variables of the pendulum are represented by $q=\left(\beta_{r}, \beta_{P}, r\right)$.

$$
\begin{aligned}
& \text { where } x=r S_{G}, y=r D, z=-r S_{r} \\
& \qquad \begin{array}{l}
S_{G}=\sin \beta_{P}, S_{r}=\sin \beta_{r}, D=\sqrt{1-S_{G}^{2}-S_{r}^{2}} \\
C_{r}=\cos \beta_{r}, C_{G}=\cos \beta_{P}
\end{array}
\end{aligned}
$$

Let $\left(\tau_{r}, f, \tau_{G}\right)$ are the actuator's torques and force effecting on the shaft at the zero point $(\mathrm{O})$ associated with the variables $\left(\beta_{r}, r, \beta_{P}\right)$, respectively; $M$ denotes the mass of the pendulum; $g$ is gravitational constant. The equation which represents the motion of a 3D inverted pendulum in Cartesian Co-ordinates system is given as follows:

$$
M\left(\begin{array}{l}
\ddot{x} \\
\ddot{y} \\
\ddot{z}
\end{array}\right)=\left(J^{T}\right)^{-1}\left(\begin{array}{l}
\tau_{r} \\
f \\
\tau_{G}
\end{array}\right)+\left(\begin{array}{l}
0 \\
-M g \\
0
\end{array}\right)
$$

Where Jacobian matrix is defined as follows:

$$
J=\frac{\partial p}{\partial q}=\left[\begin{array}{ccc}
0 & S_{G} & r C_{G} \\
-r C_{r} S_{r} / D & D & -r C_{G} S_{G} / D \\
-r C_{r} & -S_{r} & 0
\end{array}\right]
$$

Multiply left-hand and right hand side of (3) by $J^{\mathrm{T}}$, we have:

$$
M\left[\begin{array}{ccc}
0 & -r C_{r} S_{r} / D & -r C_{r} \\
S_{G} & D & -S_{r} \\
r C_{G} & -r C_{G} S_{G} / D & 0
\end{array}\right]\left(\begin{array}{c}
\ddot{x} \\
\ddot{y} \\
\ddot{z}
\end{array}\right)=\left(\begin{array}{l}
\tau_{r} \\
f \\
\tau_{G}
\end{array}\right)-M g\left(\begin{array}{c}
-r C_{r} S_{r} / D \\
D \\
-r C_{G} S_{G} / D
\end{array}\right)
$$

Using the first row of (5) we get

$$
M\left(-r D . \ddot{z}-r S_{r} . \ddot{y}\right)=\frac{D}{C_{r}} \cdot \tau_{r}+r S_{r} M g
$$

By substituting expressions (1) and (2) into (6), we obtain the equations describing the dynamics of the inverted pendulum along $\mathrm{z}$ and $\mathrm{x}$ axis, respectively :

$$
\begin{array}{r}
M(-y . \ddot{z}+z . \ddot{y})=\frac{D}{C_{r}} \cdot \tau_{r}-z \cdot M g \\
M(y . \ddot{x}-x . \ddot{y})=\frac{D}{C_{G}} \cdot \tau_{g}+x . M g
\end{array}
$$

In 3D space, the pendulum exists many different moving possibilities, however, in order to apply the equation of motion of the pendulum to the combined wearer-exoskeleton system conveniently, constraints of the motion of the pendulum should be proposed in this paper. We propose the first constraint limiting the motion in the plane defined by a given normal vector $\left(k_{\mathrm{x},}, 1, k z\right)$ and y intersection at $\mathrm{y}_{\mathrm{G}}$ 


$$
y=k_{x} x+k_{z} z+y_{G}
$$

Take the second derivate of (9) as follow:

$$
\ddot{y}=k_{x} \ddot{x}+k_{z} \ddot{z}
$$

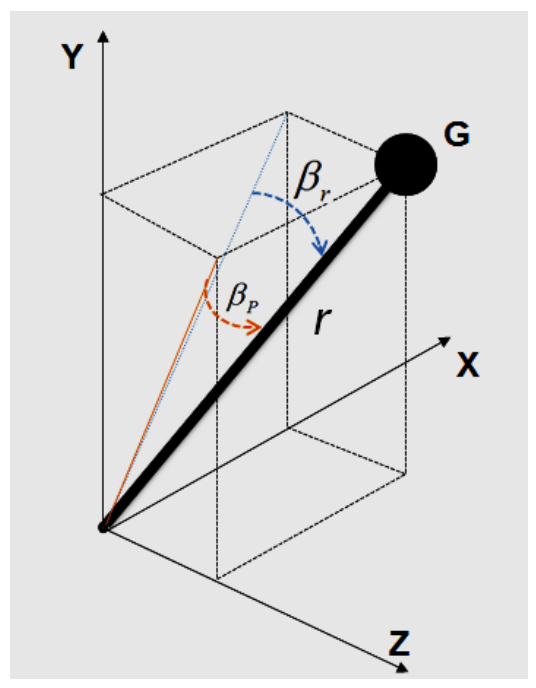

Figure 1: 3D Linear Inverted Pendulum Model

From expressions (7),(8), (9), (10), by removing y variable, we have:

$$
\begin{aligned}
& \ddot{z}=\frac{z}{y_{G}} g-\frac{k_{x}}{y_{G}}(x \ddot{z}-\ddot{x} z)-\frac{1}{M y_{G}} u_{r} \\
& \ddot{x}=\frac{x}{y_{G}} g+\frac{k_{z}}{y_{G}}(x \ddot{z}-\ddot{x} z)+\frac{1}{M y_{G}} u_{G}
\end{aligned}
$$

Where $\tau_{r}=\frac{C_{r}}{D} u_{r} ; \tau_{p}=\frac{C_{G}}{D} u_{G} ; u_{r}$ and $u_{G}$ are virtual inputs which are introduced to compensate input nonlinearity. We propose that the motion is in a plane $\left(k_{x}=k_{z}=0\right)$, and there has no input constraint torque on supporting leg in this paper, so $u_{r}=u_{G}=0$. We get:

$$
\begin{aligned}
\ddot{z} & =\frac{z}{y_{G}} g \\
\ddot{x} & =\frac{x}{y_{G}} g \\
\text { denote } \quad \mu & =\sqrt{\frac{g}{y_{G}}}
\end{aligned}
$$

From the differential equations (13),(14), we can get the solutions as follow:

$$
\begin{aligned}
x_{G} & =C_{1} e^{-\mu \cdot t}+C_{2} e^{\mu . t} \\
z_{G} & =C_{3} e^{-\mu . t}+C_{4} e^{\mu . t}
\end{aligned}
$$

Equations (16), (17) represent the projection of the center of mass $G$ on to the Oxz plane respect to time under forces and moments effecting on the actuators. Parameters $C_{1}, C_{2}, C_{3}, C_{4}$ are defined based on 
contraints and initial conditions. The such class of motion in (16) (17) can be applied to motion planing for the combined wearer - exoskeleton system so that the system still keeps the balaned state.

\section{ANALYSING THE CENTER OF MASS OF THE COMBINED WEARER- EXOSKELETON SYSTEM}

As we know that the exoskeleton is built from metal segments and these links are connected by joints that driven by actuators. Each element has own weight and the distribution of the mass is different each other. Therefore, the definition of the position of the mass is necessary in the balance control during walking. In fact, the wearer also has the different distribution of the center of mass for each body part, the parameters illustrating the distance relationship between the center of mass and the segments ends are introduced in Table 1 [10]. In addition, the exoskeleton is worn by the wearer via soft belts at specific locations and acompanies the wearer body forward, therefore, we propose that both the exoskeleton and the wearer are combined in a combined system as in Figure 1. Then, the center of mass of each segment in the combined system can be calculated and approximated by virtual center of masses in the link segment model as in Figure 1.

Table 1 Anthropometric data adapted from Winter (1990). Note that H represents the subject's body height

\begin{tabular}{|l|l|l|l|}
\hline Body segment & Lengh, L & \multicolumn{3}{|l|}{ Center of mass (\% of L) } \\
\hline & & Proximal & Distal \\
\hline Upper arm & $0.186 \mathrm{H}$ & 0.436 & 0.564 \\
Forearm & $0.146 \mathrm{H}$ & 0.43 & 0.57 \\
Hand & $0.108 \mathrm{H}$ & 0.506 & 0.494 \\
Thigh & $0.245 \mathrm{H}$ & 0.433 & 0.567 \\
Leg & $0.53 \mathrm{H}$ & 0.433 & 0.567 \\
Foot & $0.152 \mathrm{H}$ & 0.5 & 0.5 \\
HAT & $0.475520 \mathrm{H}$ & 0.626 & 0.374 \\
\hline
\end{tabular}

We consider that the 7 DOFs combined wearer - exoskeleton system includes right leg, upper body and the left leg and their virtual center of masses $(\mathrm{COM})$ are located at specific positions by $d_{r}, d_{l}, d_{b}$ distances as illustrated in Figure 2. We suppose that we got the center of mass of the combined weaer-exoskeleton system $\mathrm{G}\left(x_{G}, y_{G}, z_{G}\right)$. We consider that the mass of the pendulum and the $M$ mass are the same, and the shaft which supports $M$ mass is one of two supporting legs of the combined wearer - exoskeleton system. So the pendulum which is applied in the combined wearer - exoskeleton system has supporting shaft which switching each other according to the wearer's step. This means that the supporting shaft switching continuously from the left leg to the right leg and vice versa.

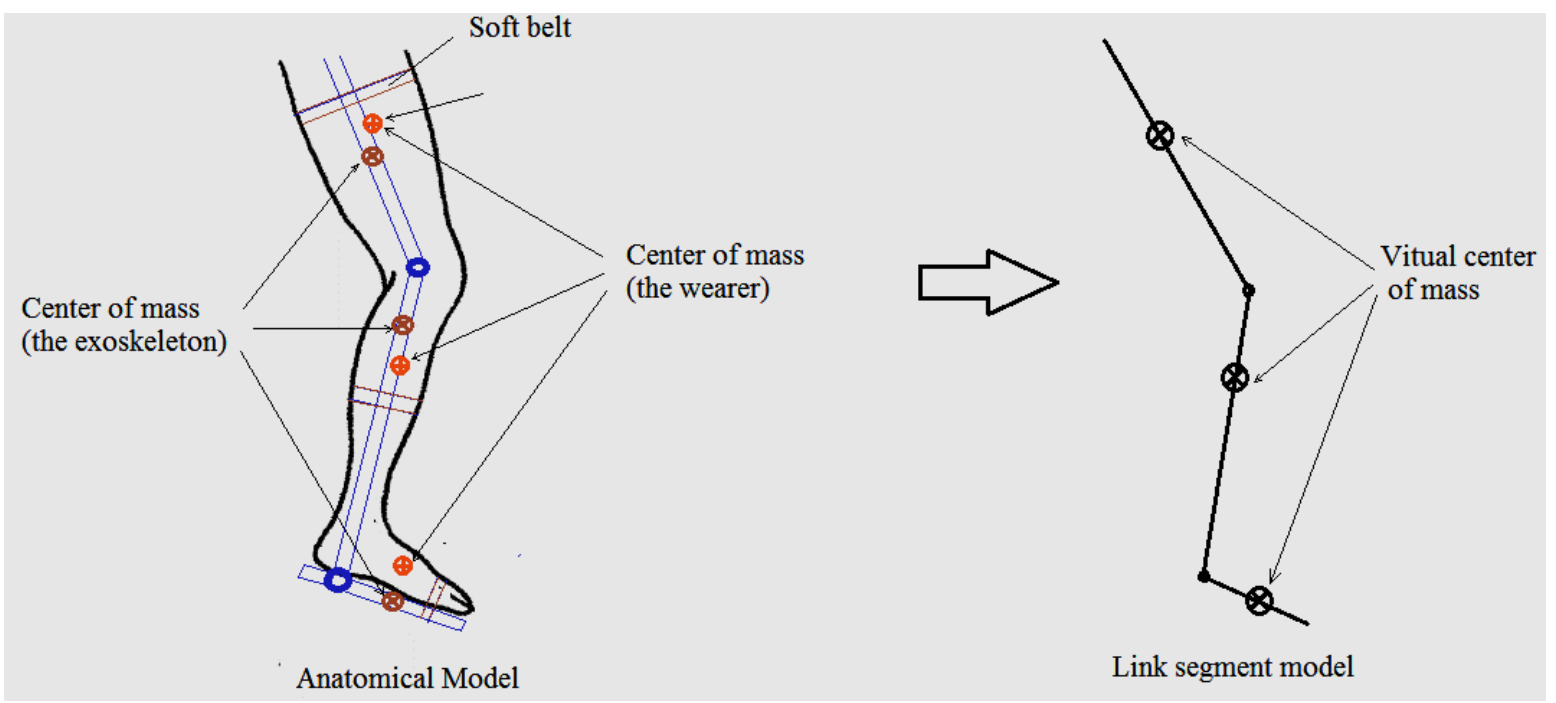

Figure 2: The combined weaer-exoskeleton system and its equivalent model (One leg model) 


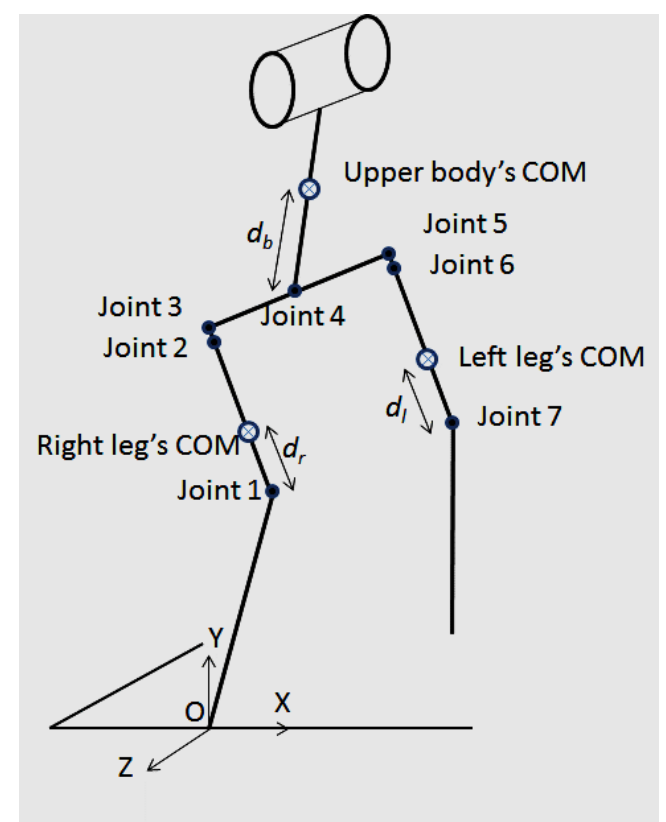

Figure 3: Center of mass distribution at each link

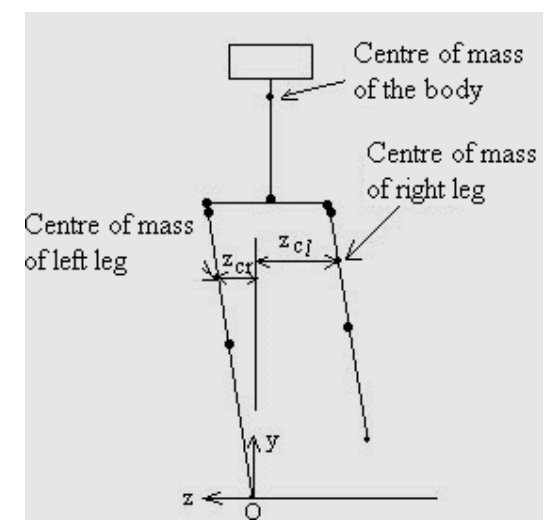

Figure 4: Mass distribution at each link (lateral and sagittal plane)

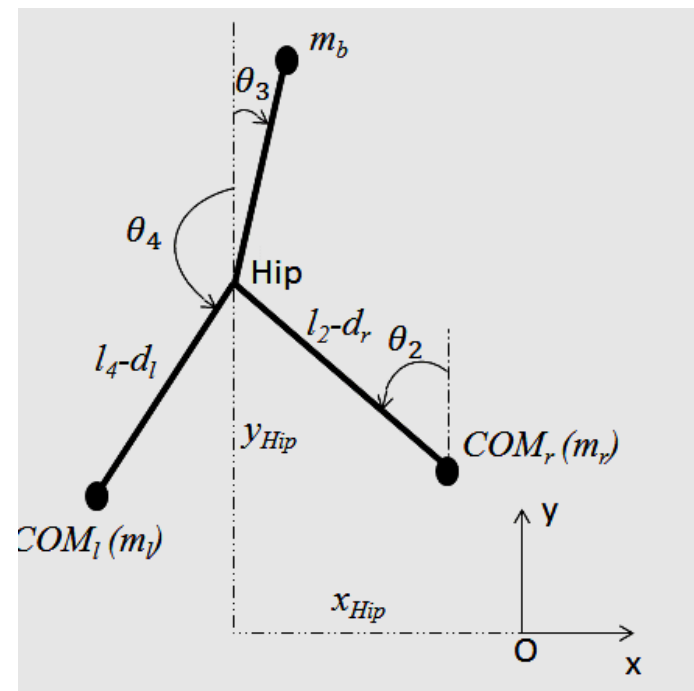

Figure 5: The center of mass's coordinates at links 
Based on the mass distribution in Figure 3, we can find out the coordinate of the center of mass of each leg and body's of the combined wearer - exoskeleton system. By synthesizing three coordinates (Center of mass of left leg, right leg and body link), the coordinate of the center of mass of whole combined system can be found in the Figure 5 as follow:

$$
\begin{aligned}
& x_{G}=x_{h}+\frac{m_{b} d_{b}}{2 m_{r}+m_{b}} \sin \theta_{3}+\left(\frac{m_{r}\left(l_{2}-d_{r}\right)}{2 m_{r}+m_{b}}\right) \times\left(\cos \theta_{l} \sin \theta_{4}-\cos \theta_{r} \sin \theta_{2}\right) \\
& y_{G}=y_{h}+\frac{m_{b} d_{b}}{2 m_{r}+m_{b}} \cos \theta_{3}+\left(\frac{m_{r}\left(l_{2}-d_{r}\right)}{2 m_{r}+m_{b}}\right) \times\left(\cos \theta_{l} \cos \theta_{4}-\cos \theta_{r} \cos \theta_{2}\right) \\
& z_{G}=y_{h} \operatorname{tg} \theta_{r}-(1 / 2) l_{6}+\left(\frac{m_{r}\left(l_{2}-d_{r}\right)}{2 m_{r}+m_{b}}\right) \times\left(\sin \theta_{l} \cos \theta_{4}-\sin \theta_{r} \cos \theta_{2}\right)
\end{aligned}
$$

Where, $\left(x_{h}, y_{h}, z_{h}\right)$ is the location coordinate of the Hip point.

\section{MOTION PLANNING FOR THE COMBINED WEARER - EXOSKELETON}

\subsection{Motion planning in single phase}

The goal in this section is to design the combined wearer-exoskeleton system's gait so that the combined wearer-exoskeleton system maintains a normal gait and does not fall. Thus we need to find constraints at the joints so that the combination of moving of rotation angles at the joints will help the combined system move in the desired trajectory, which ensures a balanced system.

During the step cycle, a normal wearer walks in two different phases: a single phase and a double phase [11]. The single phase is the phase in which only one leg supports the whole body weight and the other leg swings forward without touching the ground. The double phase is the phase in which both legs support the whole body weight and shift the body weight to the equilibrium area for the next single phase. However, it is difficult for a disable person both to keep the normal walking pattern and to prevent him/her from falling without using any assistive device. Therefore, the trajectories of the assistive exoskeleton need to be predefined according to the normal wearer's walking pattern so that the assistive exoskeleton helps the wearer to walk in the normal walking pattern. To solve this issue, the idea is to keep the center of mass (G) always fall into the equilibrium area on the walking plane. So, the projection of $G$ on the walking plane must be closed to the contact point of the supporting leg (Tip_b) on the walking plane in the single phase to ensure that the combined wearer - exoskeleton system is always in the equilibrium state.

In the double phase, the equilibrium area is bigger than the equilibrium area in the single phase because both legs support the whole mass. In this phase, the center of mass moves from the equilibrium area in a single phase to the equilibrium area in the next single phase. By this way, the center of mass is always in equilibrium areas in the single phase and the double phase during walking. Therefore, the combined wearer - exoskeleton system is always in equilibrium state. In order to design the walking pattern in the equilibrium state, we propose constraints for the combined system as follows:

1) We suggest the direction of the body is always vertical during walking. It means that $\theta_{3}$ is always equal to zero. Therefore, we have the first constraint: $\theta_{3}=0$

2) We assume that when the combined wearer - exoskeleton system moves, the right declination is equal to the left declination, so we have the second constraint: $\theta_{r}=\theta_{l}$

3) The relationship between $\mathrm{z}$ and $\mathrm{x}$ direction can be found from the equations (16) (17). The motion curve of the mass $\mathrm{M}$ in $x \mathrm{Oz}$ plane is similar to the motion pattern of the linear inverted pendulum in $x O z$ plane.

With the above contraints, the projection of $\mathrm{G}$ point on the $\mathrm{xOz}$ plane is shown as in Figure 6. 


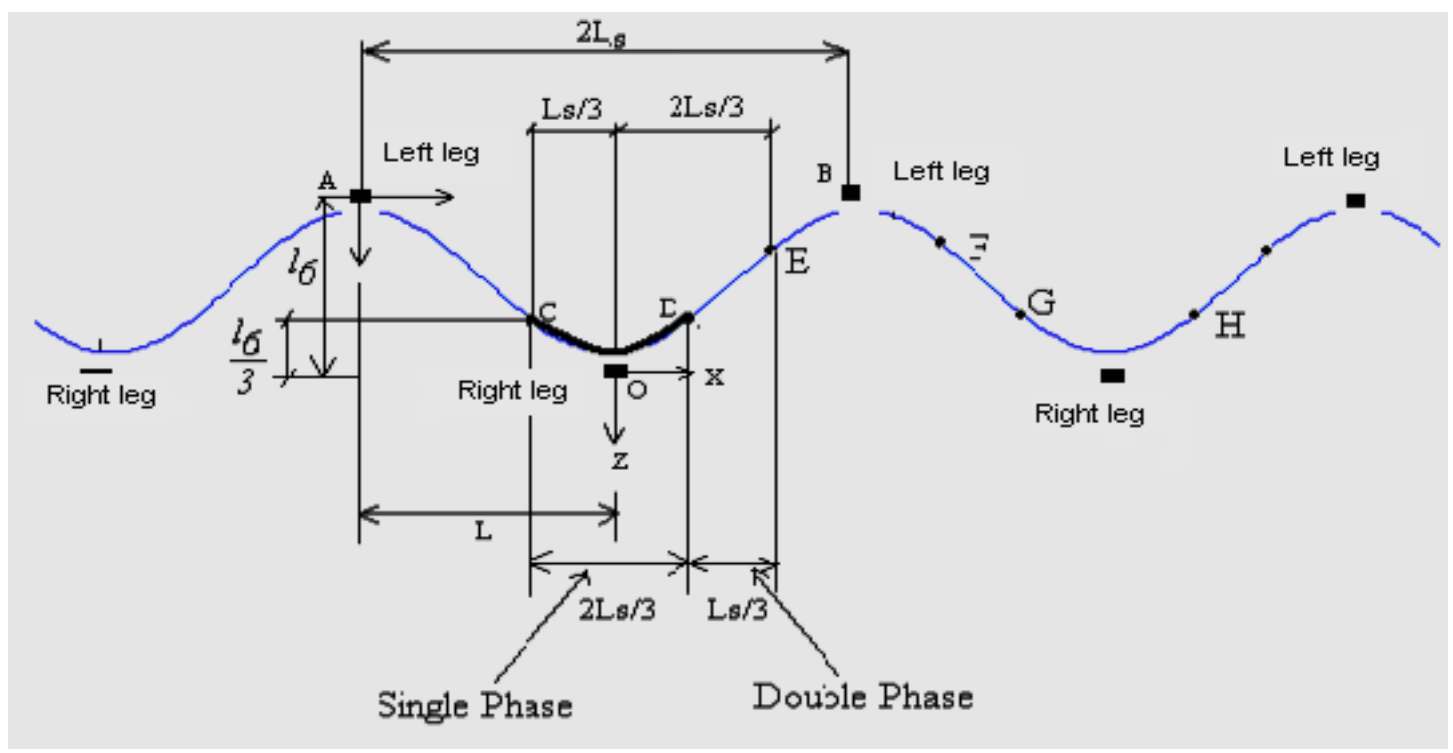

Figure 6: The trajectory of the projection of $\mathrm{G}$ on the walking plane

The bold line illustrates the trajectory of $G$ point during the single phase while the thin line illustrates the trajectory of $\mathrm{G}$ point during the double phase. According to the above predefined trajectories, the $\mathrm{G}$ point both moves forward and trends to the $\mathrm{O}$ origins in the equilibrium area during walking. These $\mathrm{O}$ origins are placed at the Tip_b of supporting leg. $L_{s}$ is denoted as the cycle step distance.

From the equations (18), (19), (20) and the constraints 1) and 2), COG coordinate equations are written as follows:

$$
\begin{gathered}
x_{G}=x_{h}+\left(\frac{m_{r}\left(l_{2}-d_{r}\right)}{2 m_{r}+m_{b}}\right) \times\left(\cos \theta_{r}\left(\sin \theta_{4}-\sin \theta_{2}\right)\right) \\
y_{G}=y_{h}+\frac{m_{b} d_{b}}{2 m_{r}+m_{b}}+\left(\frac{m_{r}\left(l_{2}-d_{r}\right)}{2 m_{r}+m_{b}}\right) \times\left(\cos \theta_{r}\left(\cos \theta_{4}-\cos \theta_{2}\right)\right) \\
z_{G}=y_{h} \operatorname{tg} \theta_{r}-(1 / 2) l_{6}+\left(\frac{m_{r}\left(l_{2}-d_{r}\right)}{2 m_{r}+m_{b}}\right) \times\left(\sin \theta_{r}\left(\cos \theta_{4}-\cos \theta_{2}\right)\right)
\end{gathered}
$$

Assuming that during movement, the center of mass of the system undulates with a very small amplitude compared to its height from the ground. Therefore, it can be assumed that the height of the center of mass is constant value $\left(y_{G}=\right.$ const $)$. This constraint condition shows that the center of mass moves in the plane which is parallel with the ground. $Y_{G}$ parameter is designed in advance according to the wearer's body size.

We have three constraints as follows:

$$
\begin{aligned}
& x_{G}=C_{1} e^{-\mu . t}+C_{2} e^{\mu \cdot t}=x_{h}+\left(\frac{m_{r}\left(l_{2}-d_{r}\right)}{2 m_{r}+m_{b}}\right) \times\left(\cos \theta_{r}\left(\sin \theta_{4}-\sin \theta_{2}\right)\right) \\
& z_{G}=C_{3} e^{-\mu . t}+C_{4} e^{\mu . t}=y_{h} \operatorname{tg} \theta_{r}-(1 / 2) l_{6}+\left(\frac{m_{r}\left(l_{2}-d_{r}\right)}{2 m_{r}+m_{b}}\right) \times\left(\sin \theta_{r}\left(\cos \theta_{4}-\cos \theta_{2}\right)\right) \\
& y_{G}=y_{G_{-} \text {const }}=y_{h}+\frac{m_{b} d_{b}}{2 m_{r}+m_{b}}+\left(\frac{m_{r}\left(l_{2}-d_{r}\right)}{2 m_{r}+m_{b}}\right) \times\left(\cos \theta_{r}\left(\cos \theta_{4}-\cos \theta_{2}\right)\right)
\end{aligned}
$$

In addition, we need to add additional constraints for Tip_e at the swinging leg. By investigating the humanoid walking gait, we propose the trajectory for Tip_e in which its x,y coordinates are defined by a 
third and fifth polynomial functions respect with time $(\mathrm{t})$, respectively $\left(x_{e}=f_{x}(t), y_{e}=f_{y}(t)\right)$. The coefficients of the polynomial functions $\left(a_{0}, a_{1}, a_{2}, a_{3}, b_{0}, b_{1}, b_{2}, b_{3}, b_{4}, b_{5}\right)$ are defined by initial constraints as the figure below:

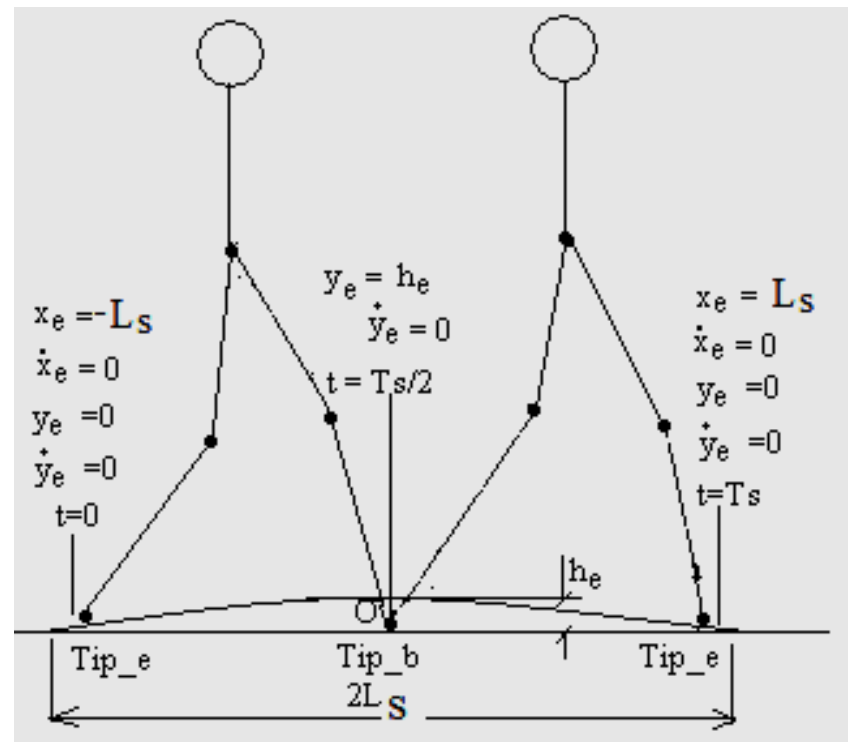

Figure 7: Designed trajectory of the Tip_e

$$
\begin{aligned}
& x_{e}=\left(l_{1} \sin \theta_{1}+l_{2} \sin \theta_{2}+l_{4} \sin \theta_{4}+l_{5} \sin \theta_{5}\right) \cos \theta_{r}=a_{0}+a_{1} t+a_{2} t^{2}+a_{3} t^{3} \\
& y_{e}=\left(l_{1} \cos \theta_{1}+l_{2} \cos \theta_{2}+l_{4} \cos \theta_{4}+l_{5} \cos \theta_{5}\right) \cos \theta_{r}=b_{0}+b_{1} t+b_{2} t^{2}+b_{3} t^{3}+b_{4} t^{4}+b_{5} t^{5}
\end{aligned}
$$

where, $L_{s}$ is the step distance, $h_{e}$ is the maximum distance of the Tip_e from the ground. These parameters are designed according to the wearer's body.

We can find out joint angle variables $\theta_{1}, \theta_{2}, \theta_{4}, \theta_{5}, \theta_{r}$, and $\theta_{3}=0, \theta_{r}=\theta_{l}$ from contraints in equations (24), (25), (26), (27) and (28) in the single phase.

\subsection{Motion planning in double phase}

In double phase, both legs of the combined system touch the ground to support the main body and move the center of mass forward. This helps the combined system from falling over when its center of mass is far away from the stand leg (See Figure 6). The goal of this section is to design the trajectory of the center of mass so that the combined system moves in equilibrium state. To do this, we will find the constraints at the joints for the system to follow the trajectory designed in this phase.

1) The first constraint is that we assume the angle of the wearer's main body relative to the vertical is very small. Hence we have the first contraint $\theta_{3}=0$

2) The second constraint is that the angle of inclination to the left and right is the same during moving, It means that $\theta_{r}=\theta_{l}$

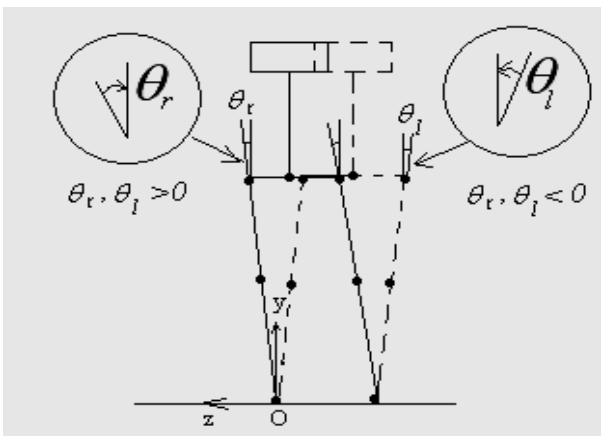

Figure 8: The tilt angle to the left and right of the wearer 
In Figure 8, the wearer is leaning to the right (dashed lines). The center of mass of the whole system (the wearer and exoskeleton) is focusing on the right foot. In this phase, the wearer has to move their body forward and leans to one side to lift the other leg for the next step. The constraint $\theta_{r}=\theta_{l}$ ensures that the combined system is leaned evenly on both legs.

3) Constraint of centre of mass $G$ for the combined system

Switching from single phase to double phase has a continuity of starting and ending position of each phase (D and $\mathrm{E}$ points in Fig.6). Therefore, we have a contraints for y coordinate of $\mathrm{G}$ point

$$
y_{G}=y_{G_{-} \text {const }}
$$

In order to keep the combined system in an equilibrium state, $G$ point should be on the DE straight line To do this, we design $\mathrm{x}_{\mathrm{G}}$ and $\mathrm{z}_{\mathrm{G}}$ coordinates by equations

$$
\begin{aligned}
& x_{G}=c_{0}+c_{1} t \\
& z_{G}=d_{0}+d_{1} t\left(0 \leq t \leq T_{D}\right)
\end{aligned}
$$

By substituting (29), (30), (31) into (21), (22), (23) the contraints of G point are given as follows:

$$
\begin{aligned}
& x_{G}=c_{0}+c_{1} . t=x_{h}+\left(\frac{m_{r}\left(l_{2}-d_{r}\right)}{2 m_{r}+m_{b}}\right) \times\left(\cos \theta_{r}\left(\sin \theta_{4}-\sin \theta_{2}\right)\right) \\
& y_{G}=y_{G_{-} \text {const }}=y_{h}+\frac{m_{b} d_{b}}{2 m_{r}+m_{b}}+\left(\frac{m_{r}\left(l_{2}-d_{r}\right)}{2 m_{r}+m_{b}}\right) \times\left(\cos \theta_{r}\left(\cos \theta_{4}-\cos \theta_{2}\right)\right) \\
& z_{G}=y_{h} t g \theta_{r}-(1 / 2) l_{6}+\left(\frac{m_{r}\left(l_{2}-d_{r}\right)}{2 m_{r}+m_{b}}\right) \times\left(\sin \theta_{r}\left(\cos \theta_{4}-\cos \theta_{2}\right)\right)
\end{aligned}
$$

We can find out joint angle variables $\theta_{1}, \theta_{2}, \theta_{4}, \theta_{5}, \theta_{r}$, and $\theta_{3}=0, \theta_{r}=\theta_{l}$ from contraints in equations (29), (30), (31), (32), (33) and (34) in the double phase.

\section{EXPERIMENTAL RESULTS}

A real augmentation exoskeleton system (called Hualex Exoskeleton at Center for Robotics, University of Electronic Science and Technology of China) is used to validate our planned trajectories. The designed parameters should be chosen in advance so that they are suitable for the weak wearer such as step distance, the height of the wearer because they affect on the wearer's walking pattern. These parameters given for the wearer of $1.7 \mathrm{~m}$ in height and of $60 \mathrm{~kg}$ in weight are given in the Table 2. The exoskeleton has the weight of $15 \mathrm{~kg}$ in total, therefore, the combined masses are denoted in the Table 2 by $m_{i}(i=1 \div 6)$ for each segments.

Table 2: Exoskeleton's mechanical paramters

\begin{tabular}{|l|l|l|l|l|l|}
\hline$l_{1}$ & 0.48 & $m_{1}(\mathrm{~kg})$ & 5.66 & Step length $L_{s}(\mathrm{~m})$ & $0.9 \mathrm{~m}$ \\
\hline$l_{2}$ & 0.42 & $m_{2}(\mathrm{~kg})$ & 9.0 & $h_{-}$tipE $(\mathrm{m})$ & $0.1 \mathrm{~m}$ \\
\hline$l_{3}$ & 0.8 & $m_{3}(\mathrm{~kg})$ & 6.62 & Walking Speed $(\mathrm{m} / \mathrm{s})$ & $0.45 \mathrm{~m} / \mathrm{s}$ \\
\hline$l_{4}$ & 0.42 & $m_{4}(\mathrm{~kg})$ & 9.0 & $Y_{G_{-} \text {const }}(\mathrm{m})$ & $1.04 \mathrm{~m}$ \\
\hline$l_{5}$ & 0.48 & $m_{5}(\mathrm{~kg})$ & 5.66 & Wearer's height & $1.75 \mathrm{~m}$ \\
\hline$l_{6}=d_{b}$ & 0.30 & $m_{6}+m_{7}(\mathrm{~kg})$ & 39.06 & & \\
\hline
\end{tabular}




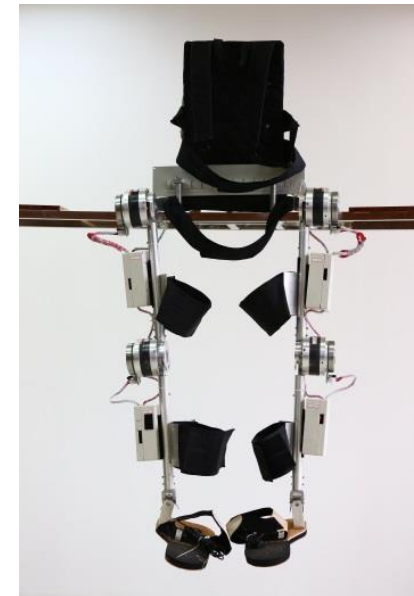

Figure 9: HUALEX Exoskeleton System

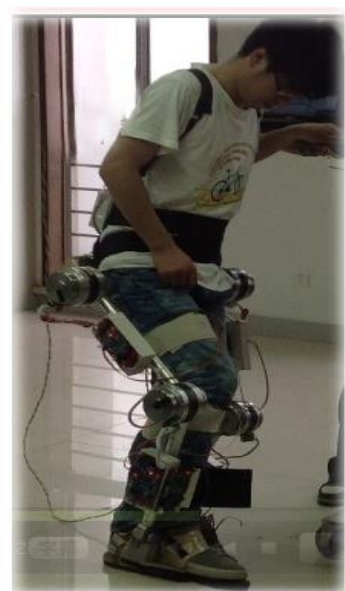

Figure 10: A paralyzed wearer is walking with the support by the augmentation exoskeleton

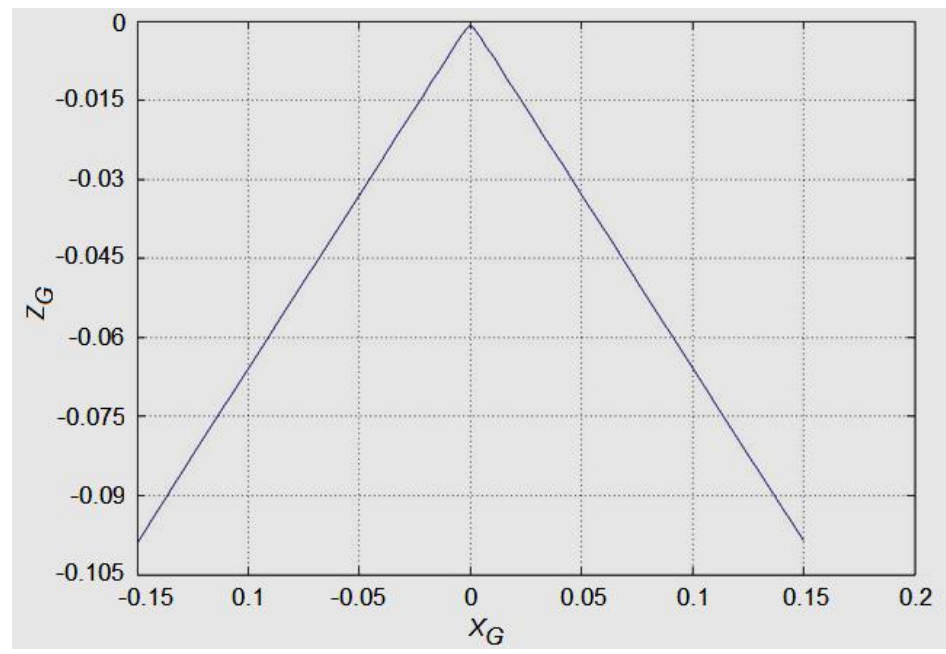

Figure 11: $\mathrm{X}_{\mathrm{G}}, \mathrm{Z}_{\mathrm{G}}$ coordinates in the single phase

Figures 11, 12, 13 show the experimental results obtained from the system's center of mass in the moving plane when compared to the planned trajectories in Figure 6. Figure 11 shows the coordinates of the center of mass in Oxz plane during single phase. This result is perfectly resonable when compared with the solid line in Figure 6 (planned trajectories). In addition, Figure 12 shows the trajectory of the swinging leg walking forward; Figure 13 shows the movement of the center of mass of the system (similar to the section from $\mathrm{D}$ to E point in Figure 6) in the double phase before lifting the legs to perform the next single phase. These experimental results satisfy pre-planned trajectories based on the inverted pendulum model. Therefore, the wearer still maintains a state of balance when moving as in Figure10. 


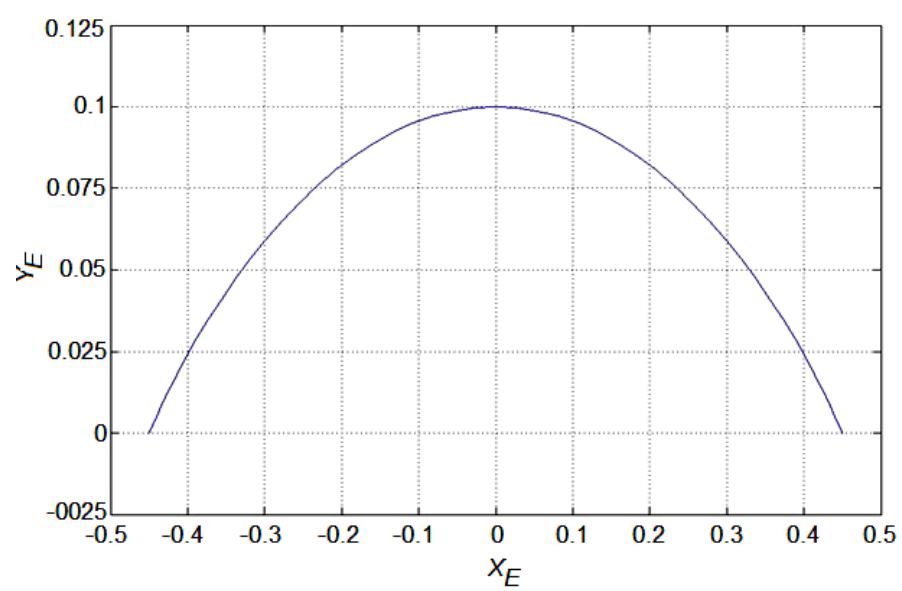

Figure 12: $\mathrm{X}_{\mathrm{E}}, \mathrm{Y}_{\mathrm{E}}$ coordinates in the single phase

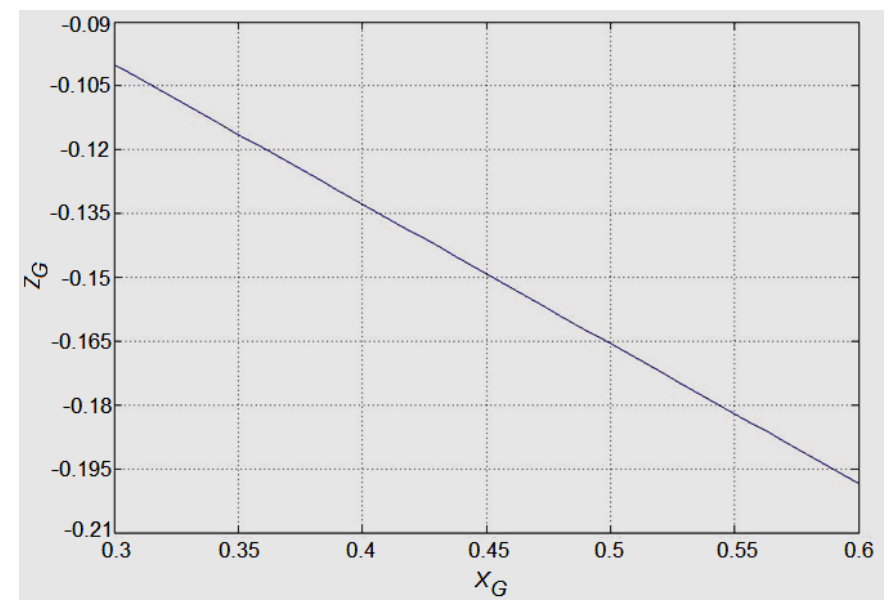

Figure 13: $\mathrm{X}_{\mathrm{G}}, \mathrm{Z}_{\mathrm{G}}$ coordinates in the double phase

\section{CONCLUSIONS}

The paper proposed motion trajectory for the exoskeleton system to support wearers with knee paralysis based on the inverted pendulum model. The reason for relying on the inverted pendulum model is that by examining the motion characteristics of the inverted pendulum, it can be seen that if exoskeleton is controlled to follow the same trajectory as the traverse of the inverted pendulum, exoskeleton can assist the wearer. Hence, the wearer can walk while maintaining a normal gait and not fall down. Experimental results on a real exoskeleton system (called HUALEX) have shown that the wearer walks slowly and does not fall, while retaining a normal gait. These results are also a prerequisite for developing an optimal gait with more phases for wearers supported by exoskeleton in next researches.

\section{ACKNOWLEDGMENT}

The research was supported by colleagues at the Center of Robotics, University of Electronic Science and Technology of China. Thanks to Mr. Hang Ming, who participated in the experiment.

\section{REFERENCES}

[1] B. Cheng, C. Hao Zhong, X.Zhao, H. Ma, A wearable exoskeleton suit for motion assistance to paralysed patients, Journal of Orthopaedic Translation, vol. 11, pp. 7-18, 2017.

[2] G. Zeilig, H.Weingarden, M.Zwecker,I.1 Dudkiewicz, A. Bloch, and A. Esquenazi, Safety and tolerance of the ReWalk ${ }^{\mathrm{TM}}$ exoskeleton suit for ambulation by people with complete spinal cord injury: A pilot study, Journal of Spinal Cord Medecine, vol. 35, no.2, pp. 96-101, 2012. 
[3] Quintero, H.A., Farris, R.J., Goldfarb, Control and implementation of a powered lower limb orthosis to aid walking in Paraplegic Individuals in IEEE Int Conf. on Rehabilitation Robotics, ICORR 2011 (2011).

[4] A. Tsukahara, Y. Hasegawa and Y. Sankai, Gait support for complete spinal cord injury patient by synchronized leg-swing with HAL, 2011 IEEE/RSJ International Conference on Intelligent Robots and Systems, San Francisco, CA, 2011, pp. 1737-1742.

[5] R. Liang et al., Design of rigid-compliant parallel exoskeleton knee joint, 2017 IEEE 3rd Information Technology and Mechatronics Engineering Conference (ITOEC), Chongqing, 2017, pp. 440-443

[6] B. Yang, H. Lee and E. Tanaka, Stable Posture Compensation Based on Zero-Moment Point Control Method for a Walking Assistance Apparatus, 2018 IEEE International Conference on Cyborg and Bionic Systems (CBS), Shenzhen, 2018, pp. 286-291.

[7] W. Yang, C. Yang, Y. Chen and L. Xu, Simulation of exoskeleton ZMP during walking for balance control, 2018 IEEE 9th International Conference on Mechanical and Intelligent Manufacturing Technologies (ICMIMT), Cape Town, 2018, pp. 172-176.

[8] I. M. Motoc, K. Sirlantzis, S. Spurgeon and P. Lee, "Zero Moment Point/Inverted Pendulum-Based Walking Algorithm for the NAO Robot," 2014 Fifth International Conference on Emerging Security Technologies, Alcala de Henares, 2014, pp. 63-66.

[9] S. Kajita et al, 3D Linear Inverted Pendulum Mode:A simple modeling for a Biped walking parttern generation, Proceedings 2001 IEEE/RSJ International Conference on Intelligent Robots and Systems, 2001, pp. 239-246.

[10] Jose L. Pons , Wearable robot: Biomechatronics Exoskeletons, John Wiley \& Son, Ltd, CSIC, Madrid Spain, 2008.

[11] K. Tsujioka, Development of Support System Modeled on Robot Suit HAL for Personalized Education and Learning, 2017 International Conference of Educational Innovation through Technology (EITT), Osaka, 2017, pp. 337-338.

\section{HOẠCH ĐỊNH CHUYỂn ĐộNG CHO HỆ KHUNG XƯƠNG HỖ TRỌ๋ PHỤC HỒI DÁNG ĐI CHO NGƯờI}

Tóm tắt. Các nghiên cứu về hệ thống khung xương phục hồi chức năng đã được thực hiện trong nhiều thập kỷ gần đây và đạt được nhiều tiến bộ. Tuy nhiên, hầu hết các nghiên cứu tập trung vào các hệ thống đơn giản hơn như hệ khung xương phục hồi chức năng cho 1 hoặc hai khớp hoặc chỉ cho một chân bị liệt với mục đích là tái tạo lại dáng đi của người mặc. Các nghiên cứu về hệ khung xương phục hồi chức năng cho toàn bộ các chân bị liệt vẫn còn rất hạn chế do tính phức tạp trong vấn đề giữ cân bằng cho người mặc. Do đó, trong những nghiên cứu gần đây hay tập trung vào việc người mặc thường dùng nạn đi kèm để hỗ trợ tránh té ngã khi di chuyển. Để khỏi phải dùng nạn hỗ trợ giúp phục hồi lại dáng đi như người bình thường, vấn đề cân bằng cho người mặc phải được xem xét trong thuật toán điều khiển. Trong bài báo này, chúng tôi xây dựng quỹ đạo chuyển động cho hệ kết hợp gồm người mặc và hệ khung xương hỗ trợ giúp đảm bảo người mặc luôn giữ thăng bằng. Các quỹ đạo hoạch định này đã được kiểm chứng trên hệ thống khung xương thực tên là HUALEX tại Trường Đại học Khoa Học và Công nghệ Điện tử Trung Quốc.

Từ khóa. Hệ khung xương phục hồi, tương tác người và hệ khung xương, tái tạo dáng di chuyển cho người.

Ngày nhận bài: 17/12/2019

Ngày chấp nhận đăng: 14/02/2020 